\title{
Golimumab: A novel human anti-TNF- $\alpha$ monoclonal antibody for the treatment of rheumatoid arthritis, ankylosing spondylitis, and psoriatic arthritis
}

\author{
This article was published in the following Dove Press journal: \\ Core Evidence \\ 22 July 2009 \\ Number of times this article has been viewed
}

\author{
Jonathan Kay' \\ Mahboob U Rahman ${ }^{2,3}$ \\ 'Division of Rheumatology, UMass \\ Memorial Medical Center, University \\ of Massachusetts Medical School, \\ Worcester, MA, USA; ${ }^{2}$ Centocor \\ Research and Development, Inc., \\ Malvern, PA, USA; ${ }^{3}$ University of \\ Pennsylvania School of Medicine, \\ Philadelphia, PA, USA
}

\begin{abstract}
Introduction: The introduction of tumor necrosis factor- $\alpha$ (TNF- $\alpha$ ) inhibitors represented a significant advance in the management of rheumatoid arthritis (RA) and other chronic inflammatory diseases. Although three TNF- $\alpha$ inhibitors have been approved for the treatment of RA by the US Food and Drug Administration (FDA) and the European Medicinal Products Evaluation Agency (EMEA), not all patients achieve a satisfactory clinical improvement with these therapeutic agents. The mode of administration of these medications is inconvenient for some patients.
\end{abstract}

Aims: Golimumab is a novel anti-TNF- $\alpha$ monoclonal antibody that is in clinical development for the treatment of RA, psoriatic arthritis (PsA), and ankylosing spondylitis (AS), either as a firstline biologic therapy or an alternative after other TNF- $\alpha$ inhibitors have been discontinued. This review summarizes the development of, and clinical evidence achieved with, golimumab.

Evidence review: Golimumab has demonstrated significant efficacy in randomized, doubleblind, placebo-controlled trials when administered subcutaneously once every four weeks. It has been generally well tolerated in clinical trials and demonstrates a safety profile comparable with currently available TNF- $\alpha$ inhibitors.

Outcomes summary: Golimumab has been confirmed to be an effective treatment for patients with RA, PsA, and AS in phase III clinical trials as evaluated by traditional measures of disease activity, such as signs and symptoms, as well as measures of physical function, patient reported outcomes, and health economic measures. The efficacy and safety profile of golimumab in RA, PsA, and AS appears to be similar to other anti-TNF agents. However, golimumab has the potential advantage of once monthly subcutaneous administration and the possibility of both subcutaneous and intravenous administration.

Keywords: golimumab, TNF- $\alpha$ inhibitors, rheumatoid arthritis, psoriatic arthritis, ankylosing spondylitis

Core evidence outcomes summary for golimumab

\begin{tabular}{|lll|}
\hline Outcome measure & Evidence & Implications \\
\hline $\begin{array}{l}\text { Patient-oriented evidence } \\
\text { Quality of life }\end{array}$ & $\begin{array}{l}\text { Substantial } \\
\text { evidence }\end{array}$ & $\begin{array}{l}\text { Golimumab improves functioning and quality } \\
\text { of life in patients with PsA }\end{array}$ \\
Tolerability & $\begin{array}{l}\text { Clear } \\
\text { evidence }\end{array}$ & Golimumab is well tolerated \\
& & \\
(Continued) \\
\hline
\end{tabular}

Correspondence: Jonathan Kay Rheumatology Center, UMass Memorial Medical Center, Memorial Campus, II 9 Belmont Street, Worcester, MA 01605, USA

Tel +l 5083346273

Fax +I 5083346038

Email jonathan.kay@umassmemorial.org

submit your manuscript | www.dovepress.com 


\begin{tabular}{|c|c|c|}
\hline \multicolumn{3}{|l|}{ (Continued) } \\
\hline Outcome measure & Evidence & Implications \\
\hline \multicolumn{3}{|l|}{ Disease-oriented evidence } \\
\hline $\begin{array}{l}\text { ACR and EULAR criteria in } \\
\text { MTX-naïve RA patients }\end{array}$ & $\begin{array}{l}\text { Substantial } \\
\text { evidence }\end{array}$ & $\begin{array}{l}\text { Equivalent to MTX; modest additional benefit } \\
\text { of adding golimumab to MTX, similar to other } \\
\text { TNF- } \alpha \text { antagonists }\end{array}$ \\
\hline $\begin{array}{l}\text { ACR and EULAR criteria in patients } \\
\text { with RA despite MTX }\end{array}$ & $\begin{array}{l}\text { Substantial } \\
\text { evidence }\end{array}$ & $\begin{array}{l}\text { Adding golimumab to MTX confers significant } \\
\text { additional benefit }\end{array}$ \\
\hline $\begin{array}{l}\text { ACR and EULAR criteria in patients } \\
\text { with RA despite previous TNF- } \alpha \\
\text { antagonist therapy }\end{array}$ & $\begin{array}{l}\text { Substantial } \\
\text { evidence }\end{array}$ & $\begin{array}{l}\text { Adding golimumab to background therapy } \\
\text { confers significant additional benefit }\end{array}$ \\
\hline $\begin{array}{l}\text { ACR criteria, PASI and MASES scores } \\
\text { in patients with PsA }\end{array}$ & $\begin{array}{l}\text { Substantial } \\
\text { evidence }\end{array}$ & $\begin{array}{l}\text { Adding golimumab to background therapy } \\
\text { confers significant additional benefit }\end{array}$ \\
\hline $\begin{array}{l}\text { ASAS, BASDAI, and BASFI } \\
\text { criteria in patients with AS }\end{array}$ & $\begin{array}{l}\text { Substantial } \\
\text { evidence }\end{array}$ & $\begin{array}{l}\text { Adding golimumab to background therapy } \\
\text { confers significant additional benefit }\end{array}$ \\
\hline \multicolumn{3}{|l|}{ Economic evidence } \\
\hline Cost effectiveness & No evidence & \\
\hline \multicolumn{3}{|c|}{$\begin{array}{l}\text { Abbreviations: ACR, American College of Rheumatology; AS, ankylosing spondylitis; ASAS, asessment in ankylosing } \\
\text { spondylitis; BASDAI, Bath Ankylosing Spondylitis Activity Index; BASFI, Bath Ankylosing Spondylitis Functional } \\
\text { Index; EULAR, European League Against Rheumatism; MASES, Maastricht Ankylosing Spondylitis Enthesitis Score; } \\
\text { MTX, methotrexate; PASI, Psoriasis Area and Severity Index; PsA, psoriatic arthritis; RA, rheumatoid arthritis. }\end{array}$} \\
\hline
\end{tabular}

\section{Introduction}

Rheumatoid arthritis (RA) is a chronic and progressive systemic inflammatory disease characterized by chronic synovial inflammation that results in cartilage damage, progressive bone erosion, and functional decline. The prevalence of RA ranges from $0.5 \%$ to $1.0 \%$ and it occurs twice as often in women as in men. ${ }^{1}$ Psoriatic arthritis (PsA) is a spondyloarthropathy occurring in patients with chronic skin inflammation that is characterized by both chronic synovial and enthesial inflammation. Although the exact prevalence of PsA is unknown, it is estimated to be between $0.3 \%$ and $1.0 \%{ }^{2}$ Ankylosing spondylitis (AS) is a spondyloarthropathy characterized by enthesial and axial skeletal inflammation that results in syndesmophyte formation with spinal fusion and also in progressive functional decline. The prevalence of AS ranges from $0.03 \%$ to $0.9 \%$ among white Europeans and East Asians and is lower among African Americans. ${ }^{1}$

Early and aggressive therapy that controls inflammation can drastically reduce or even stop the progression of joint erosion and, thus, optimize the functional ability and quality of life of patients with inflammatory polyarthritis or spondyloarthropathy..$^{3-5}$ Significant progress in elucidating the pathophysiology of RA and other chronic inflammatory diseases has led to the identification of tumor necrosis factor- $\alpha$ (TNF- $\alpha$ ) as a pivotal inflammatory mediator. ${ }^{6}$ The subsequent development of TNF- $\alpha$ inhibitors has proven to be a major advance in the treatment of RA, PsA, AS, and other chronic inflammatory diseases. Three TNF- $\alpha$ inhibitors are currently approved by the US Food and Drug Administration (FDA) for the treatment of RA, PsA, and AS: etanercept $\left(\right.$ Enbrel $\left.^{\circledR}\right)$, infliximab (Remicade ${ }^{\circledR}$ ), and adalimumab (Humira ${ }^{\circledR}$ ). Etanercept is a soluble dimeric p $75 \mathrm{TNF}-\alpha$ receptor/Fc fusion construct, ${ }^{7}$ and was the first TNF- $\alpha$ inhibitor approved for the treatment of RA. Infliximab is a chimeric mouse/human antiTNF- $\alpha$ monoclonal antibody (mAb), ${ }^{8}$ and adalimumab is a humanized anti-TNF- $\alpha \mathrm{mAb} .{ }^{9}$ As a class, TNF- $\alpha$ antagonists have been proven to control the signs and symptoms of RA and to inhibit joint destruction. In addition, TNF- $\alpha$ antagonists control the signs and symptoms of PsA and AS and markedly improve activity of skin lesions in psoriasis. Adalimumab and infliximab have been approved for the treatment of inflammatory bowel diseases as well. ${ }^{10}$

Although many patients derive significant benefit from TNF- $\alpha$ inhibitors, there remains a population of patients who do not achieve a satisfactory clinical response with the currently available agents. Despite a limited amount of empiric evidence, clinical experience has shown that patients often respond to a second TNF- $\alpha$ inhibitor when they experience lack of efficacy or waning of response to the first one. ${ }^{11,12}$ Thus, the responses of individual patients to TNF- $\alpha$ a inhibitors are not homogeneous. Two additional TNF- $\alpha$ inhibitors are currently being developed: certolizumab pegol is a pegylated Fab-fragment of an anti-TNF- $\alpha$ antibody, and golimumab (GLM) is a human anti-TNF- $\alpha$ mAb. Thus, these new TNF- $\alpha$ inhibitors will provide additional therapeutic options for patients who are not responding adequately to 
currently available anti-TNF agents. The currently available anti-TNF agents are administered either intravenously or subcutaneously. The subcutaneous agents are administered twice a week to every two weeks. GLM will provide the option of once a month SC administration, which might be more convenient for patients who are currently injecting themselves every two weeks to twice a week.

This review describes the development and molecular characterization of GLM, and the preclinical data and early clinical trial experience with this novel anti-TNF- $\alpha$ mAb in patients with RA, PsA, and AS.

\section{Pharmacology and characterization of golimumab Molecular characterization}

GLM was developed as a fully human monoclonal antibody that could inhibit TNF- $\alpha$. Human immunoglobulin (Ig) transgenic mice (Medarex, Princeton, NJ) were immunized with human TNF- $\alpha$ and the resulting antibody-secreting hybridoma clones were screened by immunoassay for human light and heavy chains that bound to human TNF- $\alpha$. These antibodies were isolated and ranked by their ability to neutralize TNF- $\alpha$ using a cytotoxicity assay. The antibody GLM consistently demonstrated high bioactivity and was cloned, sequenced, and re-expressed in transfected myeloma cells. ${ }^{13,14}$ The amino acid sequences of the constant regions of both heavy and light chains of GLM are human and thus are identical to the corresponding constant regions of infliximab. However, in contrast to the murine-derived heavy and light chain variable regions of infliximab, the corresponding variable regions of GLM are also human. ${ }^{15}$

In preclinical studies, the affinity of GLM for soluble TNF- $\alpha$ was assessed by surface plasmon resonance and kinetic exclusion assay that measure absorption and equilibrium binding affinity, respectively; the affinity for transmembrane TNF- $\alpha$ was assessed by radioimmunoassay; and TNF- $\alpha$ neutralizing capacity was assessed using several in vitro bioassays. Thermal stability was assessed by differential scanning calorimetry. GLM demonstrated high affinity for both soluble (17 pM) and transmembrane TNF- $\alpha$ (1.4 pM) and completely neutralized TNF- $\alpha$, but did not inhibit lymphotoxin or show evidence of self association. Thus, GLM is a stable, human IgG1 $\kappa \mathrm{mAb}$ that demonstrates high affinity and specificity for human TNF- $\alpha$ and can neutralize TNF- $\alpha$ bioactivity in vitro. In vivo bioactivity was assessed in murine models of arthritis and psoriasis. Notably, in a murine transgenic model of arthritis (Tg197 mouse that constitutively expresses human TNF- $\alpha$ and develops an inflammatory arthritis that resembles human RA) GLM treatment reduced disease activity. ${ }^{13,14,16}$

\section{Formulation}

GLM exhibits multiple glycoforms in solution and has predicted molecular masses ranging from 149,802 daltons to 151,064 daltons. GLM is intended for both subcutaneous (SC) and intravenous (IV) administration. For SC administration, it is manufactured in prefilled syringes and auto-injectors. Each milliliter also contains $0.87 \mathrm{mg}$ L-histidine and L-histidine hydrochloride, $41.0 \mathrm{mg}$ sorbitol, $0.15 \mathrm{mg}$ polysorbate 80 , and water. The histidine buffer formulation and GLM concentration were chosen to minimize discomfort on injection, which had been reported by patients to whom larger volumes of other biologic agents dissolved in citrate buffer were administered. ${ }^{17,18}$

\section{Pharmacokinetics}

The pharmacokinetics of GLM have been assessed in patients with RA following a single IV infusion or repeated SC injections. ${ }^{15,19}$ Noncompartmental analysis, compartmental analysis, and population pharmacokinetics were determined in a phase I trial of IV GLM, in which patients were randomized to receive placebo or GLM $0.1,0.3,1,3$, 6 , or $10 \mathrm{mg} / \mathrm{kg}$. ${ }^{15}$ GLM was generally well tolerated in this trial and its pharmacokinetics appeared to be linear over the dose range evaluated.

In a phase II trial of 50 or $100 \mathrm{mg}$ GLM administered subcutaneously, median trough GLM concentrations generally increased as the doses increased; however, there was large variability between patients. Serum GLM concentrations generally attained steady state by week 12 for all dosage groups. ${ }^{20}$

Population pharmacokinetics were also assessed in phase III trials for patients with RA. ${ }^{19}$ For this analysis, a one-compartment pharmacokinetics model with firstorder adsorption and elimination was chosen to describe the observed concentration-versus-time data. Of all covariates tested, weight, concomitant use of methotrexate (MTX), antibody-to-GLM status, and baseline C-reactive protein (CRP) were identified as significant covariates for the apparent clearance of GLM, and weight was a significant covariate for volume of distribution. ${ }^{19}$ Serum golimumab concentrations were lower in patients who were not taking MTX, had antibodies to golimumab, were heavier, and had higher serum levels of CRP. 


\section{Clinical development of golimumab}

Preclinical and phase I testing of GLM revealed no significant safety issues. There were no substantial differences between patients who received placebo and those who received GLM in incidence of infections, infusion reactions, hematology, clinical chemistry, vital signs, or electrocardiogram measurements in phase I testing. ${ }^{15}$ The clinical development program for GLM has so far included one phase II trial and four phase III trials in patients with RA, one phase III trial in patients with PsA, and one phase III trial in patients with AS.

\section{Phase II clinical trial}

A 52-week, double-blind, placebo-controlled, phase II dose-ranging study of GLM was conducted in patients with active RA despite MTX therapy. ${ }^{20}$ Patients continued to receive stable doses of MTX and were randomly assigned to each of five treatment groups in approximately equal proportions: placebo, $50 \mathrm{mg}$ GLM every four weeks, $50 \mathrm{mg}$ GLM every two weeks, $100 \mathrm{mg}$ GLM every four weeks, or $100 \mathrm{mg}$ GLM every two weeks. All patients continued to receive stable doses of MTX throughout the study (at least $10 \mathrm{mg} /$ week). Study drug or placebo was administered by SC injection every two weeks through week 20. Patients who had been receiving placebo, in addition to MTX, during the first 20 weeks of the study were switched to receive infliximab $(3 \mathrm{mg} / \mathrm{kg})+$ MTX therapy in an unblinded manner at week 20 and thereafter. The primary endpoint was the proportion of patients in the combined GLM + MTX groups and also in at least one of the individual GLM + MTX dose groups that achieved at least 20\% improvement in RA disease activity according to American College of Rheumatology response criteria (ACR20) at week 16. Secondary endpoints included ACR50 and ACR70 responses at week 16; improvement in ACR20, ACR50, and ACR70 responses over time; improvement in numeric index of ACR response (ACR-N); improvement in Disease Activity Score using 28 joints (DAS28); and improvement in Health Assessment Questionnaire (HAQ) disability scores. At week 16, $61 \%$ of the patients in the combined GLM + MTX groups and 79\% of the patients in the $100 \mathrm{mg}$ GLM every two weeks + MTX group achieved an ACR20 response, compared with $37 \%$ of the patients receiving placebo $+\operatorname{MTX}(P=0.010)$, thus achieving the primary endpoint. ${ }^{20}$ The ACR20, ACR50, and ACR70 responses were maintained through week 52 for all doses (Figure 1). Efficacy was also demonstrated by each of the secondary endpoints. ${ }^{20}$
Selection of golimumab dose for the phase III program The 52-week, double-blind, placebo-controlled, phase II dose-ranging study of GLM was designed to assess the effect of fixed doses, $50 \mathrm{mg}$ or $100 \mathrm{mg}$ administered every two or four weeks. This study was powered to detect a significant effect of the combined golimumab arms compared with placebo; it was too small, with 35 subjects randomized to each arm, to detect treatment differences between the individual golimumab dose cohorts. A significantly greater proportion of subjects achieved an ACR20 response in the combined golimumab arms than in the placebo arm $(P=0.010)$. In addition, a significantly greater proportion of subjects receiving golimumab $100 \mathrm{mg}$ every two weeks achieved an ACR20 response compared with those receiving placebo $(P<0.001)$. However, all of the golimumab dose regimens showed numerically higher proportions of subjects achieving an ACR 20 response compared with placebo, with the $50 \mathrm{mg}$ every four weeks arm approaching significance $(P=0.056)$. Among the patients taking each of the golimumab dose regimens, the proportion achieving an ACR50 response was significantly greater than among those receiving placebo, with the most robust response observed among those receiving golimumab $50 \mathrm{mg}$ every four weeks ( $40 \% ; P<0.001)$. Because of the small size of this phase II study, no difference in efficacy could be distinguished among the four arms studied. Although no difference was observed in the safety profile among the four dose arms, minimal exposure to drug is desirable. Thus, the dosages of $50 \mathrm{mg}$ and $100 \mathrm{mg}$ every four weeks were chosen for further evaluation in the phase III program, since these were the lowest potentially effective golimumab doses and were considered to provide the most convenient dosing regimen for patients.

\section{Phase III clinical trials}

GLM is being evaluated for the treatment of RA, PsA, and AS in several phase III trials: three trials in patients with RA treated with SC GLM, one trial in patients with RA treated with IV GLM, one trial in patients with PsA treated with SC GLM, and one trial in patients with AS treated with SC GLM. This review will focus on the five phase III trials of SC GLM for which 24-week data from the RA and AS trials ${ }^{21-25}$ and 52-week data from the PsA trial ${ }^{26}$ were presented at the 2008 European League Against Rheumatism (EULAR) Annual Scientific Meeting (Table 1). Each of the studies was designed to include endpoints that measure signs and symptoms of disease, functional disability, radiographic progression, and health-related outcomes. Thus far, GLM has demonstrated efficacy consistent with that of the currently 


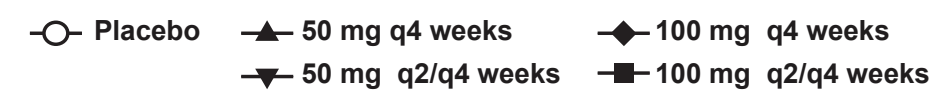

A

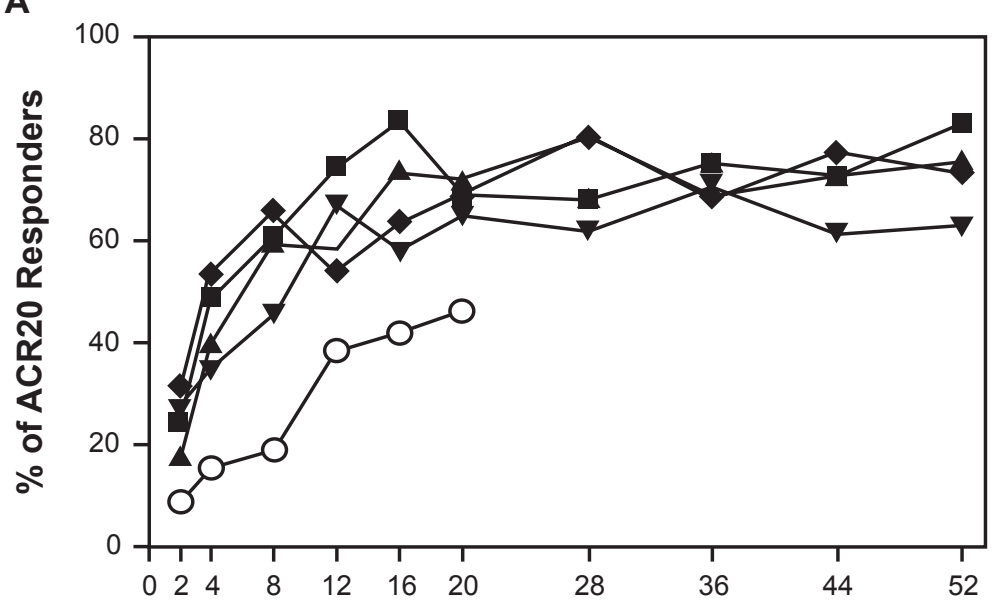

B
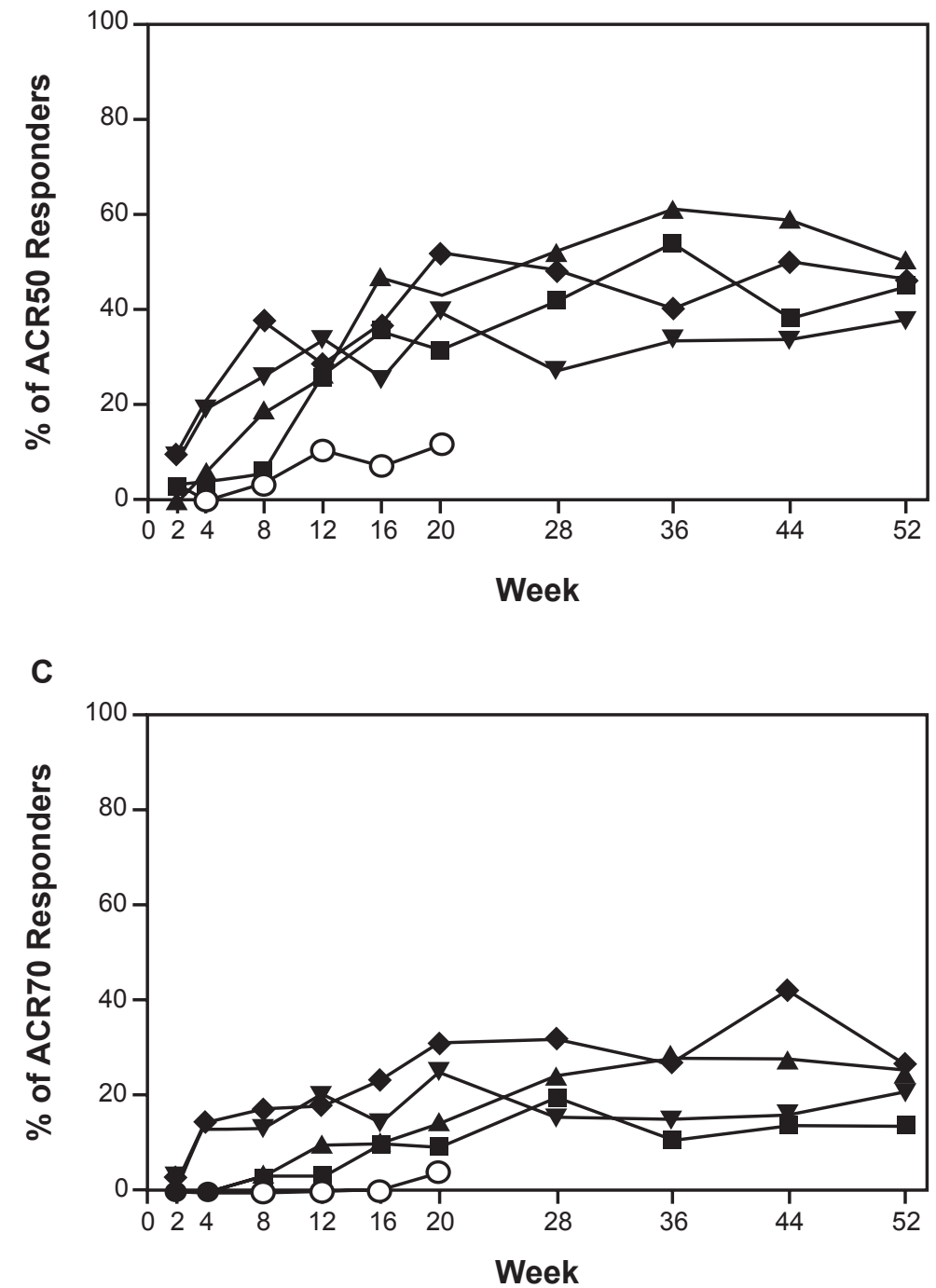

Figure I Efficacy was maintained through 52 weeks in patients with active rheumatoid arthritis despite prior treatment with methotrexate. Percentage of patients meeting the American College of Rheumatology 20\% improvement (ACR20) criteria (A), 50\% improvement (ACR50) criteria (B), and 70\% improvement (ACR70) criteria (C) through week 52. Copyright (C) 2008, American College of Rheumatology. Reprinted with permission from Kay J, Matteson EL, Dasgupta B, et al. Golimumab in patients with active rheumatoid arthritis despite treatment with methotrexate: a randomized, double-blind, placebo-controlled, dose-ranging study. Arthritis Rheum. 2008 ;58(4):964-975. 
available TNF- $\alpha$ antagonists for all standard endpoints assessed. Additional endpoints were included in these trials to assess prospectively the effects of GLM on the long-term consequences of chronic inflammation and on patient quality of life.

\section{Rheumatoid arthritis}

Three phase III trials of SC administration of GLM have been conducted in three different subgroups of patients with RA. The GO-BEFORE trial was designed to assess the efficacy and safety of GLM administered every four weeks as monotherapy or in combination with MTX in patients with active RA who had not been previously treated with MTX (MTX-naïve). In this multicenter, double-blind, placebo-controlled trial, 637 patients were randomized to one of four treatment arms (Table 1). Among these patients, the median duration of disease ranged from 1.0 to 1.8 years. The co-primary endpoints of the study were the proportion of patients who achieved ACR50 at week 24 and the change from baseline in van der Heijde Sharp (vdHS) score at week 52. To account for multiple comparisons, the prespecified hierarchical statistical testing was conducted for primary and major secondary endpoints. The combined GLM (50 mg and $100 \mathrm{mg}$ ) + MTX group was compared first with MTX alone and, if significant at
$P=0.05$ level, a pairwise comparison between GLM $50 \mathrm{mg}+$ MTX and GLM $100 \mathrm{mg}+$ MTX was performed. If this test was positive, the noninferiority comparison between GLM $100 \mathrm{mg}$ alone and MTX alone would be performed.

By intent-to-treat (ITT) analysis, the primary endpoint of a greater proportion of patients in GLM (50 mg and $100 \mathrm{mg})+$ MTX groups compared with MTX alone group achieving an ACR50 response at week 24 was not achieved. ${ }^{22}$ Nonetheless, when a modified ITT (mITT) analysis was performed that excluded three patients who were randomized but discontinued study participation before receiving any study treatment, the primary endpoint was achieved. ${ }^{22}$ The statistical significance of this difference, however, was borderline in both the ITT and MITT analyses. In the mITT analysis the proportion of patients treated with GLM $50 \mathrm{mg}+$ MTX achieving an ACR50 response at week 24 was significantly greater than the proportion of those treated with MTX alone. GLM alone was noninferior to MTX alone. Although the additional benefit of adding GLM to MTX in this patient population was modest, it was similar to that which has been observed in previous studies of other TNF- $\alpha$ antagonists in patients with early RA who had not been previously treated with MTX, such as the ERA trial of etanercept, ${ }^{3}$ the PREMIER trial of adalimumab, ${ }^{4}$ and the ASPIRE trial of infliximab. ${ }^{27}$ GLM

Table I Phase III trial design for GLM administered subcutaneously

\begin{tabular}{|c|c|c|c|c|}
\hline Trial name & Population ${ }^{c}$ & $\mathbf{n}$ & Treatment arms ${ }^{a}$ & Primary endpoint \\
\hline GO-BEFORE & $\begin{array}{l}\text { MTX-naive patients with } \\
\text { active } \text { RA }^{\text {b }}\end{array}$ & 637 & $\begin{array}{l}\text { Placebo + MTX } \\
\text { GLM } 100 \mathrm{mg}+\text { Placebo } \\
\text { GLM } 50 \mathrm{mg}+\text { MTX } \\
\text { GLM } 100 \mathrm{mg}+\text { MTX }\end{array}$ & $\begin{array}{l}\text { ACR50 wk } 24 \\
\text { vdHS wk } 52\end{array}$ \\
\hline GO-FORWARD & $\begin{array}{l}\text { Patients with active RA } \\
\text { despite MTX treatment }\end{array}$ & 444 & $\begin{array}{l}\text { Placebo + MTX } \\
\text { GLM } 100 \mathrm{mg}+\text { Placebo } \\
\text { GLM } 50 \mathrm{mg}+\text { MTX } \\
\text { GLM } 100 \mathrm{mg}+\text { MTX }\end{array}$ & $\begin{array}{l}\text { ACR20 wk } 14 \\
\text { HAQ wk } 24\end{array}$ \\
\hline GO-AFTER & $\begin{array}{l}\text { Patients with active RA } \\
\text { despite previous treatment } \\
\text { with TNF- } \alpha \text { inhibitor(s) }\end{array}$ & 461 & $\begin{array}{l}\text { Placebo } \\
\text { GLM } 50 \mathrm{mg} \\
\text { GLM } 100 \mathrm{mg}\end{array}$ & ACR20 wk I4 \\
\hline GO-REVEAL & $\begin{array}{l}\text { Adult PsA patients with skin } \\
\text { and nail disease }\end{array}$ & 405 & $\begin{array}{l}\text { Placebo } \\
\text { GLM } 50 \mathrm{mg} \\
\text { GLM } 100 \mathrm{mg}\end{array}$ & ACR20 wk 14 \\
\hline GO-RAISE & Adult patients with active $\mathrm{AS}^{d}$ & 356 & $\begin{array}{l}\text { Placebo } \\
\text { GLM } 50 \mathrm{mg} \\
\text { GLM } 100 \mathrm{mg}\end{array}$ & ASAS 20 wk 14 \\
\hline
\end{tabular}

Notes: a All GLM treatments were administered once every four weeks, and MTX treatment once every week. ${ }^{b} \mathrm{Active}$ rheumatoid arthritis; $\geq 4$ tender joint count and $\geq 4$ swollen joint count. 'Patients continued to receive MTX, sulfasalazine, or hydroxychloroquine if they were receiving them at baseline. ${ }^{\mathrm{d}} \mathrm{According}$ to the modified New York criteria. ${ }^{30}$

Abbreviations: ACR, American College of Rheumatology; AS, ankylosing spondylitis; ASAS, ASsessment in Ankylosing Spondylitis; GLM, golimumab; HAQ, Health Assessment Questionnaire; MTX, methotrexate; PsA, psoriatic arthritis; RA, rheumatoid arthritis;TNF, tumor necrosis factor; wk, week; vdHS, van der Heijde Sharp. 
plus MTX demonstrated greater efficacy than placebo plus MTX for most of the secondary endpoints at week 24, which included DAS28 response (75.5\% for both GLM $50 \mathrm{mg}$ and $100 \mathrm{mg}+$ MTX versus $60.6 \%$ for placebo + MTX), DAS28 remission (38.4\% GLM $50 \mathrm{mg}$ and $37.7 \%$ GLM $100 \mathrm{mg}$ versus $28.1 \%$ placebo + MTX), and improvement in CRP levels (57\% GLM $50 \mathrm{mg}$ and 63\% GLM $100 \mathrm{mg}$ versus 25\% placebo + MTX) in the prespecified ITT population. Further, GLM alone was noninferior to MTX alone in all measures of efficacy evaluated. ${ }^{22}$

Therefore, although this trial did not meet its prespecified primary endpoint, the efficacy of GLM in this MTX-naïve patient population with RA was supported by the outcome of most the other endpoints evaluated, and was similar to that which has been demonstrated for other TNF- $\alpha$ antagonists in MTX-naïve patients with early RA.,4 The coprimary endpoint of inhibition of radiographic progression at week 52 is yet to be reported for this trial.

The GO-FORWARD trial was designed to assess the efficacy and safety of GLM in patients with active RA despite MTX therapy. This multicenter double-blind, placebo-controlled trial of 444 patients included both GLM monotherapy and GLM + MTX combination treatment arms (Table 1). Patients could enter early escape if they did not achieve at least $20 \%$ improvement in both swollen and tender joint counts at week 16. Statistical analysis for this trial was performed as described above. The coprimary endpoints were the proportion of patients who achieved ACR20 at week 14 and the improvement from baseline in HAQ at week 24. Both primary endpoints were met. ${ }^{24}$ Both $50 \mathrm{mg}$ GLM + MTX and $100 \mathrm{mg}$ GLM + MTX were comparable in efficacy and achieved statistical significance for all secondary endpoints at 24 weeks including ACR50, ACR70, DAS28 (using CRP) responders, and DAS28 (CRP) remission. ${ }^{24}$ Results from this trial confirm the efficacy of GLM in patients with active RA despite MTX therapy that was observed in the phase II trial, ${ }^{20}$ and demonstrate that $50 \mathrm{mg}$ GLM or $100 \mathrm{mg}$ GLM administered every four weeks in combination with MTX significantly reduces signs and symptoms and improves physical function in patients with RA.

The GO-AFTER trial was designed to assess the efficacy of an anti-TNF- $\alpha$ agent in patients with active RA despite previous treatment with other TNF- $\alpha$ antagonist(s). In this multicenter, double-blind, placebo-controlled prospective trial, 461 patients were randomized to three treatment arms (Table 1) and could enter early escape if they did not achieve at least $20 \%$ improvement in both swollen and tender joint counts at week 16 . The primary endpoint was the proportion of patients achieving an ACR20 response at week 14 for the combined GLM groups based on the prespecified hierarchical statistical test procedure described above. All patients had been treated previously with at least one TNF- $\alpha$ inhibitor: 115 patients $(24.9 \%)$ had been treated with two TNF- $\alpha$ inhibitors, and 43 patients $(9.3 \%)$ had previously received all three commercially available TNF- $\alpha$ inhibitors. ${ }^{25}$ Patients had discontinued prior TNF- $\alpha$ antagonist therapy because of lack of efficacy (58.4\%), intolerance (16.5\%), or "other reasons" (39.7\%), most often financial. Among patients with active RA who received prior anti-TNF- $\alpha$ therapy and discontinued for any reason, GLM significantly reduced signs and symptoms of RA and improved physical function at week 24 as assessed by ACR20, ACR50, and improvement in HAQ scores $(P<0.001$ for all measures for each GLM treatment arm compared individually with placebo) ${ }^{25}$ Among patients who had discontinued prior TNF- $\alpha$ antagonist therapy because of lack of efficacy, $35.7 \%$ and $42.7 \%$ of patients in the GLM $50 \mathrm{mg}$ and $100 \mathrm{mg}$ groups, respectively, achieved an ACR20 response at week 14 compared with $17.7 \%$ in the placebo group $(P<0.001) .{ }^{25}$ GLM treatment similarly resulted in significant improvements in DAS28 response and remission. Serious adverse events and serious infections occurred at a lower rate among GLM-treated patients, but these randomized controlled trials were not powered to detect statistically significant differences in relatively rare adverse events. ${ }^{25}$

This study is the first double-blind, placebo-controlled prospective trial to demonstrate the efficacy of an anti-TNF- $\alpha$ agent in patients with active RA despite previous treatment with other TNF- $\alpha$ antagonist(s), and supports the use of GLM in patients who have experienced loss of efficacy, or are intolerant, to treatment with another TNF- $\alpha$ inhibitor.

\section{Psoriatic arthritis}

The GO-REVEAL trial was designed to assess the efficacy and safety of GLM in reducing the signs and symptoms of active PsA and associated skin and nail disease. In this multicenter, randomized, placebo-controlled trial, 405 patients received placebo, or GLM 50 or $100 \mathrm{mg}$ (Table 1). The primary endpoint was the proportion of patients that achieved an ACR20 response at week 14 stratified by MTX use, which was permitted but not required. Additional endpoints included the Psoriasis Area and Severity Index (PASI) scores, improvement in enthesitis and dactylitis, and resolution of nail involvement.

After 52 weeks of treatment, GLM improved signs and symptoms of PsA significantly better than did placebo 
$(P<0.001$; GLM 50 or $100 \mathrm{mg}) \cdot{ }^{23,26}$ Concomitant use of MTX did not affect efficacy. All comparisons between GLM 50 or $100 \mathrm{mg}$ with placebo, including HAQ scores, ACR50, ACR70, DAS28 responders, and PASI scores were significant at week 24 ( $P<0.001$ for all measures). ${ }^{26}$ The effect of GLM on physical function and self-reported productivity of patients with PsA, as well as on time lost from work by caregivers of patients, was also assessed. Patients treated with GLM demonstrated significantly greater improvement from baseline in physical function, as measured by Short Form-36 (SF-36) physical component summary scores (PCS), SF-36 mental component summary scores (MCS), and HAQ scores, as well as in self-reported productivity and caregiver time lost from work at both weeks 14 and 24, compared to those treated with placebo. ${ }^{28}$ Thus, GLM treatment not only significantly improved signs and symptoms of active PsA but also enhanced physical function and health-related quality of life.

Additional endpoints in the GLM PsA trial assessed the effects of GLM treatment on nail disease, dactylitis, and enthesitis, which are features of PsA that significantly affect patients but are not typically measured in clinical trials of drug therapies for PsA. The Nail Psoriasis Severity Index (NAPSI), which analyzes the single worst psoriasisaffected nail, was used to evaluate nail involvement. The Nail Physician's Global Assessment (NPGA) was used to evaluate all fingernails (scored from 1 to $5 ; 1=$ absence of; $5=$ very severe). Dactylitis was assessed in each digit of both hands and feet and enthesis tenderness was scored in 15 body sites using the PsA-modified (with plantar fascia added) Maastricht Ankylosing Spondylitis Enthesitis Score (MASES). When administered SC every four weeks, GLM 50 or $100 \mathrm{mg}$ significantly improved psoriatic nail changes, enthesitis, and dactylitis. ${ }^{29}$ Taken together, these data demonstrate that GLM treatment of patients with PsA improves signs and symptoms of articular, cutaneous, and entheseal disease, as well as physical function and quality of life.

\section{Ankylosing spondylitis}

The GO-RAISE trial was designed to evaluate the efficacy of GLM in treating the signs and symptoms of active AS. In this multicenter, randomized, double-blind, placebocontrolled study, 356 patients with definite AS based on the modified New York criteria, ${ }^{30}$ a Bath AS Disease Activity Index (BASDAI) score $\geq 4$, and a back pain score of $\geq 4$ were randomly assigned to receive SC injections of placebo or GLM 50 or 100 mg every four weeks (Table 1). Randomization was stratified by CRP level. The primary endpoint was the proportion of patients with at least a $20 \%$ improvement in the Assessment in AS working group (ASAS) criteria at week 14 and was achieved in the trial (59.4\% and 60.0\% GLM $50 \mathrm{mg}$ and $100 \mathrm{mg}$, respectively, versus $21.8 \%$ placebo; $P<0.001) .{ }^{21}$ Clinical benefit was observed as early as four weeks after GLM treatment, and efficacy was maintained through week 24 . In addition, other than for change in the Bath AS Metrology Index (BASMI) scores, all secondary endpoints were achieved at week 14. These included ASAS40, ASAS5/6, ASAS partial remission, and the Bath AS Functional Index (BASFI). ${ }^{21}$

Data from this trial were used to assess a novel measure of health-related quality of life for patients with AS: the relationship between functionality, as measured by the BASFI, and improvements in sleep, as measured by the Jenkins Sleep Evaluation Questionnaire (JSEQ). Treatment with GLM resulted in significant $(P<0.001)$ improvements in both BASFI and JSEQ at week 14 compared with placebo. ${ }^{31}$ Moreover, there was a positive correlation between change from baseline in BASFI and change from baseline in JSEQ at week 14 in the GLM-treated groups that was not observed in the placebo-treated group $(r=0.30$, $P=0.0005$ for GLM $50 \mathrm{mg} ; r=0.44, P<0.0001$, for GLM $100 \mathrm{mg}$; versus $r=0.11, P=0.34$ for placebo). ${ }^{31-33}$ Overall, GLM improved the signs and symptoms of AS, as well as physical function and sleep of patients with active AS, through 24 weeks of treatment.

\section{Comorbidities of chronic inflammatory disease}

Patients with chronic inflammatory diseases, such as RA, are at increased risk to develop comorbid conditions..$^{34,35}$ The risks of developing coronary artery disease, insulin resistance, anemia, infection, and malignancies - lymphoma in particular - are increased among patients with RA. ${ }^{34,35}$ A 2005 Mayo Clinic study found that RA patients have a twofold increased risk of developing heart disease that is independent of traditional risk factors such as diabetes, alcohol abuse, elevated cholesterol, blood pressure, and body mass index. ${ }^{36,37}$ The consequences of RA may lead to premature mortality; the mean life expectancy for patients with RA is reduced by between 5 to 10 years. ${ }^{38}$ Increasing evidence suggests that chronic inflammation contributes to the development of these long-term complications of RA. ${ }^{39}$

The effects of GLM therapy on markers of comorbidities of chronic inflammatory disease have been assessed prospectively in the phase III trials of GLM in RA, PsA, and AS (Tables 2, 3, and 4). Patients with anemia (according to 
Table 2 Results achieved with golimumab in patients with RA

\begin{tabular}{|c|c|c|c|c|c|}
\hline \multirow{2}{*}{$\begin{array}{l}\text { Study and } \\
\text { treatment groups (n) }\end{array}$} & \multicolumn{5}{|c|}{ Outcome (\% of patients, level of significance vs placebo) } \\
\hline & ACR20 & ACR50 & ACR70 & EULAR response & EULAR remission \\
\hline \multicolumn{6}{|l|}{ GO-BEFORE } \\
\hline Placebo sc + MTX po (160) & 49.4 & 29.4 & 15.6 & 61.3 & 11.3 \\
\hline GLM 100 mg sc + placebo po (159) & 51.6 (noninferior) & 32.7 (noninferior) & I3.8 (noninferior) & 67.3 (noninferior) & I5.7 (noninferior) \\
\hline GLM 50 mg sc + MTX po (I59) & $61.6(P=0.028)$ & $40.3(P=0.042)$ & $23.9(P=0.064)$ & $73(P=0.027)$ & $25.2(P=0.001)$ \\
\hline GLM 100 mg sc + MTX po (159) & $61.6(P=0.028)$ & $36.5(P=0.177)$ & $18.2(P=0.535)$ & $76.7(P=0.003)$ & $19.5(P=0.04)$ \\
\hline \multicolumn{6}{|l|}{ GO-FORWARD } \\
\hline Placebo sc + MTX po (133) & 27.8 & 13.5 & 5.3 & 42.1 & 6 \\
\hline GLM I00 mg sc + placebo po (133) & $35.3(P=0.187)$ & $19.5(P=0.187)$ & $11.3(P=0.075)$ & $51.9(P=0.11)$ & $12(P=0.087)$ \\
\hline GLM 50 mg sc + MTX po (89) & $59.6(P<0.00 \mathrm{I})$ & $37.1(P<0.001)$ & $20.2(P<0.00 \mathrm{I})$ & $71.9(P<0.001)$ & $20.2(P=0.001)$ \\
\hline GLM 100 mg sc + MTX po & $59.6(P<0.001)$ & $32.6(P<0.001)$ & $14.6(P=0.017)$ & $76.4(P<0.00 I)$ & $22.5(P<0.001)$ \\
\hline \multicolumn{6}{|l|}{ GO-AFTER } \\
\hline Placebo sc (I55) & 16.9 & 5.2 & 3.2 & 24.5 & 2.6 \\
\hline GLM 50 mg sc (I53) & $34(P<0.001)$ & $18.3(P<0.00 \mid)$ & $11.8(P=0.004)$ & $46.4(P<0.001)$ & $10.5(P<0.001)$ \\
\hline GLM I00 mg sc (153) & $43.8(P<0.001)$ & $20.3(P<0.001)$ & $10.5(P<0.00 \mathrm{I})$ & $60.8(P<0.001)$ & $15.7(P<0.00 \mathrm{I})$ \\
\hline
\end{tabular}

Abbreviations: ACR20, 50, 70, American College of Rheumatology 20\%, 50\%, and 70\% improvement; EULAR, European League Against Rheumatism; GLM, golimumab; MTX, methotrexate; RA, rheumatoid arthritis; po, orally; sc, subcutaneously.

laboratory standards) at baseline were analyzed on entry into each of the five clinical trials of SC GLM (GO-BEFORE, GO-FORWARD, GO-AFTER, GO-RAISE, and GOREVEAL), and a subset of patients with anemia of chronic disease (anemic and ferritin level $\geq 60 \mathrm{ng} / \mathrm{mL}$ ) was also analyzed. ${ }^{40}$ In the RA, PsA, and AS studies, 20\%, 9\%, and $15 \%$ of patients respectively, had anemia at baseline. GLM treatment significantly improved anemia compared with placebo. ${ }^{40}$ Associations between the change in hemoglobin (Hb) levels and that in the SF-36 vitality scale or that in physical function, as measured using the HAQ disability index, were assessed through week 24. Hb increased significantly more in RA, AS, and PsA patients treated with GLM than in those treated with placebo, and a significantly greater number of GLM-treated patients achieved normal $\mathrm{Hb}$ levels. Significantly greater improvement in SF-36 vitality scores was observed in patients treated with GLM, and the pooled analysis demonstrated a correlation between increases in $\mathrm{Hb}$ levels and improvement in SF-36 vitality scores $(r=0.23, P=0.0071)$. Analysis of biomarkers for cardiovascular disease and insulin resistance is ongoing to determine whether GLM treatment might also reduce the likelihood of developing these comorbidities of chronic inflammation.

\section{Safety}

In clinical trials, the safety profile of GLM is comparable to those of other TNF- $\alpha$ inhibitors ${ }^{41}$ As a class, TNF- $\alpha$

Table 3 Results achieved with golimumab in patients with PsA

\begin{tabular}{|c|c|c|c|c|c|}
\hline \multirow{2}{*}{$\begin{array}{l}\text { Study and treatment } \\
\text { groups }(n)\end{array}$} & \multicolumn{5}{|c|}{ Outcome (\% of patients, level of significance vs placebo) } \\
\hline & ACR20 & ACR50 & ACR70 & PASI75 & $\begin{array}{l}\text { MASES index } \\
\text { (for enthesitis) }\end{array}$ \\
\hline \multicolumn{6}{|l|}{ GO-REVEAL } \\
\hline Placebo sc (II3) & 12.4 & 3.2 & 0.9 & I & 11.7 \\
\hline GLM 50 mg sc (I46) & $52.1(P<0.001)$ & $32.2(P<0.001)$ & $18.5(P<0.00 \mid)$ & $56(P<0.00 I)$ & $60(P<0.001)$ \\
\hline GLM I00 mg sc (146) & 61 & 37.7 & 21.2 & 66 & 66.7 \\
\hline
\end{tabular}

Note: aedian \% improvement.

Abbreviations: ACR20, 50, 70, American College of Rheumatology 20\%, 50\%, and 70\% improvement; GLM, golimumab; MTX, methotrexate; MASES, Maastricht Ankylosing Spondylitis Enthesitis Score; PASI, Psoriasis Area and Severity Index; PsA, psoriatic arthritis; po, orally; sc, subcutaneously. 
Table 4 Results achieved with golimumab in patients with AS

\begin{tabular}{|c|c|c|c|c|c|}
\hline \multirow{2}{*}{$\begin{array}{l}\text { Study and treatment } \\
\text { groups }(n)\end{array}$} & \multicolumn{5}{|c|}{ Outcome (\% of patients, level of significance vs placebo) } \\
\hline & ASAS20 & ASAS40 & $\begin{array}{l}\text { ASAS partial } \\
\text { remission }\end{array}$ & $\begin{array}{l}\text { BASDAI (50\% } \\
\text { improvement) }\end{array}$ & BASFI score \\
\hline \multicolumn{6}{|l|}{ GO-RAISE } \\
\hline Placebo sc (78) & 23.1 & 15.4 & 5.1 & 14.7 & 0.03 \\
\hline GLM 50 mg sc (138) & $55.8(P<0.00 I)$ & $43.5(P<0.001)$ & $23.2(P<0.001)$ & $50.8(P<0.00 I)$ & $-1.64(P<0.001)$ \\
\hline GLM 100 mg sc (140) & $65.7(P<0.00 I)$ & $54.3(P<0.001)$ & $21.9(P<0.001)$ & $47.8(P<0.00 I)$ & $-1.60(P<0.001)$ \\
\hline
\end{tabular}

Abbreviations: AS, ankylosing spondylitis;ASAS20, 40, ASessment in Ankylosing Spondylitis 20\% and 40\% improvement; BASDAI, Bath Ankylosing Spondylitis Activity Index; BASFI, Bath Ankylosing Spondylitis Functional Index; GLM, golimumab; MTX, methotrexate; po, orally; sc, subcutaneously.

inhibitors are associated with an increased risk of developing opportunistic infections and lymphoma, although the increased incidence of lymphoma observed in patients with RA treated with these drugs may not be higher than that which occurs in the overall population of patients with RA. $^{42}$ Reactivation of latent tuberculosis (TB) can occur in patients treated with TNF- $\alpha$ inhibitors; therefore, routine TB screening and treatment of latent TB, if present, is recommended before initiating treatment with any agent in this therapeutic class. ${ }^{12}$

In the GLM phase II trial, the most common adverse events reported were nausea, headache, injection site erythema, and worsening of RA disease activity. No cases of TB or lymphoma occurred, and the overall rate of infection in GLM-treated patients was comparable to that of the placebo group. ${ }^{20}$

GLM treatment was also well tolerated by patients enrolled in all five phase III trials of SC GLM, and reports of adverse events were consistent between the RA, AS, and PsA study populations. Serious adverse events were reported in $2.3 \%$ to $9.7 \%$ of patients among all treatment arms, and serious infections were reported in $0.7 \%$ to $5.6 \%$ of patients. One case of bone TB infection was reported in a patient receiving GLM $50 \mathrm{mg}+$ MTX in the GO-BEFORE trial. Notably, injection site reactions were reported at lower frequencies ( 0 to $10.5 \%$ ) than with the other SC TNF- $\alpha$ antagonists, etanercept and adalimumab, possibly because of the unique formulation of GLM with a histidine buffer in a small volume. Malignancies were reported in GOBEFORE (two patients treated with placebo + MTX, one patient treated with GLM $50 \mathrm{mg}+$ MTX, one patient treated with GLM 100 mg + MTX); GO-FORWARD (one patient treated with placebo + MTX, one patient treated with GLM $100 \mathrm{mg}+$ MTX, one patient treated with GLM $100 \mathrm{mg}$ monotherapy) and GO-REVEAL (three patients treated with GLM 100 mg).
Analyses for the detection of antibodies to GLM were performed with a bridging immunoassay in which GLM was used to capture and detect antibodies to GLM. Antibodies against GLM were detected in a small number of patients in all studies. Antibodies to GLM were detected in seven $(6.5 \%)$ of the 107 GLM-treated patients (five patients in the GLM $50 \mathrm{mg}$ dose groups and two patients in the GLM $100 \mathrm{mg}$ dose groups) at week 48 of the phase II trial in patients with RA. ${ }^{20}$ None of the patients who were positive for antibodies to GLM experienced a severe injection site reaction or serious adverse event, and none discontinued study agent because of lack of efficacy. ${ }^{20}$ Rates of anti-GLM antibody detection reported for the phase III trials were similar to or less than those observed for other anti-TNF monoclonal antibodies in clinical trials and ranged from $3.7 \%$ (GO-AFTER) to $4.6 \%$ (GO-REVEAL) of GLM-treated patients. ${ }^{25,26}$

\section{Outcomes summary}

GLM is a new human anti-TNF- $\alpha$ monoclonal antibody that blocks the action of TNF- $\alpha$ both in in vitro and animal disease models. GLM has been confirmed to be an effective treatment for patients with RA (including those naïve to MTX, those inadequately responsive to MTX, and those previously treated with a TNF inhibitor), AS, and PsA in phase III clinical trials that have included traditional measures of disease activity and functional decline. The safety and tolerability of GLM are comparable to that of other TNF- $\alpha$ inhibitors. With SC administration every four weeks, GLM may effectively control disease activity with less frequent dosing than the other commercially available SC TNF- $\alpha$ antagonists. Structural progression after 52 weeks of GLM therapy has been measured, but the results are not yet available. The cost-effectiveness, efficacy, and toxicity of GLM relative to currently available agents and over the longer term remain to be established. 


\section{Acknowledgments}

We thank Melissa K. Callahan $\mathrm{PhD}$ for editorial assistance, and Centocor, Inc. for providing financial support for her services. JK has received grant support from Centocor, Amgen, Genentech, Pfizer, Elan Pharmaceuticals, and Novartis; and consulting fees from Abbott, Amgen, Array BioPharma, Centocor, Novarits, Roche, Bristol-Myers Squibb, Genentech, UCB, and Wyeth. MUR is an employee of Centocor Research and Development, a wholly owned subsidiary of Johnson \& Johnson, and owns Johnson \& Johnson stock.

\section{References}

1. Helmick CG, Felson DT, Lawrence RC, et al. Estimates of the prevalence of arthritis and other rheumatic conditions in the United States. Part I. Arthritis Rheum. 2008;58:15-25.

2. Gladman DD, Antoni C, Mease P, Clegg DO, Nash, P. Psoriatic arthritis: epidemiology, clinical features, course, and outcome. Ann Rheum Dis. 2005;64:ii14-ii17.

3. Bathon JM, Martin RW, Fleischmann RM, et al. A comparison of etanercept and methotrexate in patients with early rheumatoid arthritis. N Engl J Med. 2000;343:1586-1593.

4. Breedveld FC, Weisman MH, Kavanaugh AF, et al. The PREMIER study: A multicenter, randomized, double-blind clinical trial of combination therapy with adalimumab plus methotrexate versus methotrexate alone or adalimumab alone in patients with early, aggressive rheumatoid arthritis who had not had previous methotrexate treatment. Arthritis Rheum. 2006;54:26-37.

5. Goekoop-Ruiterman YP, de Vries-Bouwstra JK, Allaart CF, et al. Clini$\mathrm{cal}$ and radiographic outcomes of four different treatment strategies in patients with early rheumatoid arthritis (the BeSt study): A randomized, controlled trial. Arthritis Rheum. 2008;58:S126-S135.

6. Brennan FM, Maini RN, Feldmann M. TNF alpha-a pivotal role in rheumatoid arthritis? Br J Rheumatol. 1992;31:293-298.

7. Moreland LW, Schiff MH, Baumgartner SW, et al. Etanercept therapy in rheumatoid arthritis. A randomized, controlled trial. Ann Intern Med. 1999;130:478-486.

8. Lipsky PE, van der Heijde DM, St Clair EW, et al. Infliximab and methotrexate in the treatment of rheumatoid arthritis. Anti-Tumor Necrosis Factor Trial in Rheumatoid Arthritis with Concomitant Therapy Study Group. N Engl J Med. 2000;343:1594-1602.

9. Weinblatt ME, Keystone EC, Furst DE, et al. Adalimumab, a fully human anti-tumor necrosis factor alpha monoclonal antibody, for the treatment of rheumatoid arthritis in patients taking concomitant methotrexate: the ARMADA trial. Arthritis Rheum. 2003; 48:35-45.

10. Behm BW, Bickston SJ. Tumor necrosis factor-alpha antibody for maintenance of remission in Crohn's disease. Cochrane Database Syst Rev. 2008;1:CD006893.

11. van Vollenhoven R, Harju A, Brannemark S, Klareskog L. Treatment with infliximab (Remicade) when etanercept (Enbrel) has failed or vice versa: data from the STURE registry showing that switching tumour necrosis factor alpha blockers can make sense. Ann Rheum Dis. 2003;62:1195-1198.

12. Furst DE, Breedveld FC, Kalden JR, et al. Updated consensus statement on biological agents for the treatment of rheumatic diseases, 2007. Ann Rheum Dis. 2007;66(Suppl 3):iii2-iii22.

13. Shealy D, Cai A, Nesspor T, et al. Characterization of golimumab (CNTO 148), a novel monoclonal antibody specific for human TNF $\alpha$ [abstract]. Ann Rheumatic Dis. 2007;66:151.

14. Shealy DJ, Visvanathan S. Anti-TNF antibodies: lessons from the past, roadmap for the future. Handb Exp Pharmacol. 2008;(181): 101-129.
15. Zhou H, Jang H, Fleischmann RM, et al. Pharmacokinetics and safety of golimumab, a fully human anti-TNF-alpha monoclonal antibody, in subjects with rheumatoid arthritis. $J$ Clin Pharmacol. 2007; 47:383-396.

16. Keffer J, Probert L, Cazlaris H, et al. Transgenic mice expressing human tumour necrosis factor: a predictive genetic model of arthritis. EMBOJ. 1991;10:4025-4031.

17. Jorgesen JT, Romsing J, Rasmussen M, Moller-Sonnergaard J, Vang L, Masaeus L. Pain assessment of subcutaneous injections. Ann Pharmacother. 1996;30:729-732.

18. Kappelgaard AM, Bojesen A, Skydsgaard K, Sjogren I, Laursen T. Liquid growth hormone: preservatives and buffers. Horm Res. 2004; 62(Suppl 3):98-103.

19. Xu Z, Hu C, Vu T, et al. Population pharmacokinetics of golimumab, an anti-tumor necrosis factor-alpha human monoclonal antibody, in patients with rheumatoid arthritis [abstract]. Ann Rheum Dis. 2008;67:627.

20. Kay J, Matteson EL, Dasgupta B, et al. Golimumab in patients with active rheumatoid arthritis despite treatment with methotrexate: a randomized, double-blind, placebo-controlled, dose-ranging study Arthritis Rheum. 2008;58:964-975.

21. Inman RD, Davis JC Jr, Heijde D, et al. Efficacy and safety of golimumab in patients with ankylosing spondylitis: results of a randomized, double-blind, placebo-controlled, phase III trial. Arthritis Rheum. 2008;58:3402-3412.

22. Emery P, Fleischmann R, Moreland L, et al. Golimumab, a new human anti-TNF-alpha monoclonal antibody, administered subcutaneously every 4 weeks in methotrexate-naïve patients with active rheumatoid arthritis: A randomized, double-blind, placebo-controlled, GO-BEFORE Study [abstract]. Ann Rheum Dis. 2008;67:179.

23. Kavanaugh A, McInnes I, Mease P, et al. Golimumab, a new human tumor necrosis factor alpha antibody, administered every four weeks as a subcutaneous injection in psoriatic arthritis: Twenty-four-week efficacy and safety results of a randomized, placebo-controlled study. Arthritis Rheum. 2009;60:976-986.

24. Keystone EC, Genovese MC, Klareskog L, et al; GO-FORWARD Study. Golimumab, a human antibody to tumour necrosis factor $\alpha$ given by monthly subcutaneous injections, in active rheumatoid arthritis despite methotrexate therapy: the GO-FORWARD Study. Ann Rheum Dis. 2009;68:789-796.

25. Smolen JS, Kay J, Doyle MK, et al.; for the GO-AFTER study investigators. Golimumab in patients with active rheumatoid arthritis after treatment with tumour necrosis factor alpha inhibitors (GO-AFTER study): a multicentre, randomised, double-blind, placebo-controlled, phase III trial. Lancet. 2009 Jun 26. [Epub ahead of print].

26. Kavanaugh A, Mack M, Beutler A, et al. Golimumab, a New, human, TNF alpha antibody administered subcutaneously every 4 weeks in psoriatic arthritis patients: 52-week efficacy and safety results of the randomized, placebo-controlled GO-REVEAL study [abstract]. Ann Rheum Dis. 2008;67:99.

27. St Clair EW, van der Heijde DM, Smolen JS, et al; Active-Controlled Study of Patients Receiving Infliximab for the Treatment of Rheumatoid Arthritis of Early Onset Study Group. Combination of infliximab and methotrexate therapy for early rheumatoid arthritis: a randomized, controlled trial. Arthritis Rheum. 2004;50(11):3432-3443.

28. Mease $\mathrm{P}$, Kavanaugh A, Livingston J, et al. Golimumab significantly improves physical function, health-related quality of Life, productivity, and reduces time lost from work for caregivers in patients with active psoriatic arthritis [abstract]. Ann Rheum Dis. 2008;67:572.

29. Gladman D, Gómez-Reino J, Mease P, et al. Golimumab, a new human TNF-alpha antibody, administered every 4 weeks as a subcutaneous injection In psoriatic arthritis: Nail, enthesitis, and dactylitis response in the randomized, placebo-controlled, GO-REVEAL study [abstract]. Ann Rheum Dis. 2008;67:526.

30. van der Linden S, Valkenburg HA, Cats A. Evaluation of diagnostic criteria for ankylosing spondylitis. A proposal for modification of the New York criteria. Arthritis Rheum. 1984;27:361-368. 
31. Deodhar A, Hsu B, Buchanan J, et al. Golimumab significantly improves sleep in patients with active ankylosing spondylitis: Results from the Phase 3 GO-RAISE Study [abstract]. Ann Rheum Dis. 2008;67:383.

32. Buchanan J, Gathany T, Hsu B, Parasuraman S. Improving functionality improves sleep in patients with active ankylosing spondylitis: Results from the GO-RAISE Study [abstract]. Ann Rheum Dis. 2008; 67:646.

33. Parasurman S, Buchanan J, Hsu B, Gathany T. Is there a relationship between functionality and productivity in patients with active ankylosing spondylitis? Resullts from the GO-RAISE study [abstract]. Ann Rheum Dis. 2008;67:574.

34. Scott DL, Kingsley GH. Tumor necrosis factor inhibitors for rheumatoid arthritis. N Engl J Med. 2006;355:704-712.

35. Turesson C, McClelland RL, Christianson TJ, Matteson EL. Severe extra-articular disease manifestations are associated with an increased risk of first ever cardiovascular events in patients with rheumatoid arthritis. Ann Rheum Dis. 2007;66:70-75.

36. Maradit-Kremers H, Crowson CS, Nicola PJ, et al. Increased unrecognized coronary heart disease and sudden deaths in rheumatoid arthritis: a population-based cohort study. Arthritis Rheum. 2005;52: $402-411$.
37. Maradit-Kremers H, Nicola PJ, Crowson CS, Ballman KV, Gabriel SE. Cardiovascular death in rheumatoid arthritis: a population-based study. Arthritis Rheum. 2005;52:722-732.

38. Kvien TK. Epidemiology and burden of illness of rheumatoid arthritis. Pharmacoeconomics. 2004;22:1-12.

39. Keystone EC. Strategies to control disease in rheumatoid arthritis with tumor necrosis factor antagonists-an opportunity to improve outcomes. Nat Clin Pract Rheumatol. 2006;2:594-601.

40. Furst D, Buchanan J, Rahman M, et al. Golimumab, a new human anti-TNF-alpha monoclonal antibody administered subcutaneously every 4 weeks, improves anemia and well-being in patients with rheumatoid arthritis, psoriatic arthritis, or ankylosing spondylitis [abstract]. Ann Rheum Dis. 2008;67:181.

41. Gartlehner G, Hansen RA, Jonas BL, Thieda P, Lohr KN. The comparative efficacy and safety of biologics for the treatment of rheumatoid arthritis: a systematic review and metaanalysis. J Rheumatol. 2006;33:2398-2408.

42. Askling J, Fored CM, Baecklund E, et al. Haematopoietic malignancies in rheumatoid arthritis: lymphoma risk and characteristics after exposure to tumour necrosis factor antagonists. Ann Rheum Dis. 2005;64:1414-1420.
Core Evidence

\section{Publish your work in this journal}

Core Evidence is an international, peer-reviewed open-access journal evaluating the evidence underlying the potential place in therapy of drugs throughout their development lifecycle from preclinical to postlaunch. The focus of each review is to evaluate the case for a new drug or class in outcome terms in specific indications and patient

\section{Dovepress}

groups. The manuscript management system is completely online and includes a very quick and fair peer-review system, which is all easy to use. Visit http://www.dovepress.com/testimonials.php to read real quotes from published authors. 